\title{
Influence of Process Conditions on the Local Solidification and Microstructure During Laser Metal Deposition of an Intermetallic TiAl Alloy (GE4822)
}

\begin{abstract}
SILJA-KATHARINA RITTINGHAUS and JONAS ZIELINSKI
Temperature-time cycles are essential for the formation of microstructures and thus the mechanical properties of materials. In additive manufacturing, components undergo changing temperature regimes because of the track- and layer-wise build-up. Because of the high brittleness of titanium aluminides, preheating is used to prevent cracking. This also effects the thermal history. In the present study, local solidification conditions during the additive manufacturing process of Ti-48Al-2Cr-2Nb with laser metal deposition (LMD) are investigated by both simulation and experimental investigations. Dependencies of the build-up height, preheating temperatures, process parameters and effects on the resulting microstructure are considered, including the heat treatment. Solidification conditions are found to be dependent on the build height and thus actual preheating temperature, process parameters and location in the melt pool. Influences on both chemical composition and microstructure are observed. Resulting differences can almost be balanced through post heat treatment.
\end{abstract}

https://doi.org/10.1007/s11661-021-06139-2

(C) The Author(s) 2021

\section{INTRODUCTION}

DUE to the high aluminum content, titanium aluminides are highly resistant against oxidation and corrosion. Thus, the requirements for applications at high temperature and under pressure loads are fulfilled by this class of materials. The current generations of low-pressure turbines (LPT) installed on GE GEnX-1B and PW1100G TiAl blades are used and manufactured by General Electric $(\mathrm{GE})^{[1]}$ and MTU Aero Engines. ${ }^{[2]}$ Therefore, airplanes of the A320neo, A321neo and Boeing 787 (Dreamliner) families fly every day with many TiAl blades. For manufacturing of these blades, cast and forging processes are established. The effort involved in shaping the intermetallic material is great owing to the low ductility and fracture toughness combined with its high oxygen affinity. Therefore, the interest in tool-free additive manufacturing of TiAl parts is high.

The alloy GE4822 is a peritectic solidified $\gamma$-titanium aluminide alloy of the historically second generation of titanium aluminides. Developed and patented by GE in

SILJA-KATHARINA RITTINGHAUS is with the Fraunhofer Institute for Laser Technology ILT, Steinbachstr. 15, 52074 Aachen, Germany. Contact e-mail: siljakatharina.rittinghaus@ilt.fraunhofer.de JONAS ZIELINSKI is with the RWTH Aachen Universityã Digital Additive Production, Campus Boulevard 79, 52072 Aachen, Germany. Manuscript submitted June 4, 2020, accepted December 21, 2020.

Article published online February 4, 2021 the 1980s, GE4822 has been used for LPT blades in GEnX turbines since 2006. The nominal composition is Ti-48Al-2Cr-2Nb at. pct, which equals Ti-33,4Al-4,8Nb-2,7Cr in wt pct with a density of 3.97 $\mathrm{g} / \mathrm{cm}^{3} \cdot{ }^{3]}$ Chromium and niobium increase the number of stacking faults and thus the material's strength. The microstructure of the solidified material is typically nearly lamellar with $\alpha_{2}-\mathrm{Ti}_{3} \mathrm{Al}+\gamma$-TiAl colonies and small amounts of $\alpha_{2}, \gamma$ and $\beta / \beta_{0}$. Hot isostatic pressing at $1150{ }^{\circ} \mathrm{C}$ to $1200{ }^{\circ} \mathrm{C}$ forms a duplex microstructure with significant fractions of equiaxed $\gamma$-TiAl. The phase distribution is highly dependent on the selected post heat treatment, e.g., as reported in References 4,5.

European research on additive manufacturing (AM) of GE4822 with a focus on electron beam melting (EBM) is performed by, e.g., Politecnico de Torino in cooperation with Avio Aero/GE Avitation and their partners. ${ }^{[6]}$ German partners are involved in both national (e.g., ProTiAl, GREAT 2020) and international (e.g., TiAl-CHARGER, E-BREAK) projects. ${ }^{[7,8]}$ The AM of other alloys is investigated as well, e.g., TNM $(-\mathrm{B} 1)^{[5]}$ or alloys with higher niobium contents. ${ }^{[9]}$ The successful building of a turbo-charger out of GE4822 with EBM was demonstrated. ${ }^{[10]}$ EBM manufactured GE4822 turbine blades are currently being tested under real conditions. ${ }^{[11]}$ Researchers from the $\mathrm{US}^{[12]}$ and $\mathrm{Asia}^{[13]}$ are also reporting findings regarding EBM of TiAl. Activities in selective laser melting (SLM), also known as laser powder bed fusion (LPBF), of TiAl are mainly focused on processing TNM alloys. $^{[14-16]}$ While for manufacturing the powder 
bed-based AM route is most promising, for repair applications laser metal deposition (LMD), also known as direct energy deposition (DED), is most suitable for building on existing 3D parts. Findings regarding the process development of LMD for titanium aluminides were reported in previous studies. ${ }^{[17,18]}$

$\mathrm{AM}$ of $\mathrm{TiAl}$ requires high preheating temperatures to allow crack-free building. The temperature of the substrate for the production of crack-free material must be in the brittle-ductile transition range $\left(550{ }^{\circ} \mathrm{C}\right.$ to $800{ }^{\circ} \mathrm{C}$ ) for titanium-based alloys. The actual preheating temperature required for LMD of TiAl depends on the alloy, geometry and process parameters. Even by preheating the substrate to $300{ }^{\circ} \mathrm{C}$, thin-walled volumes of $\mathrm{Ti}-48 \mathrm{Al}-2 \mathrm{Cr}-2 \mathrm{Nb}$ at. pet can be built up without cracks, ${ }^{[17]}$ since rapid self-heating reduces the process-related stresses and cooling rates. ${ }^{[19]}$ By both preheating of the material in the processing zone and reheating through the layer-wise build-up, the resulting microstructure is highly influenced. Regarding repair applications, the similarity of the original and added material is of special interest. Existing models allow predicting the solidification conditions during LMD by FE simulation ${ }^{[20]}$ (e.g., Inconel $\left.{ }^{\circledR} 718\right)$. Approaches to modeling a hollow cylinder-shaped structure show a good fit for Ti-48Al-2Cr. ${ }^{[21]}$ In this study, the influence of different preheating temperatures and process parameters on the solidification of GE4822 (Ti-48Al-2Cr-2Nb at. pct) built by LMD is investigated by simulation and experimental testing. Thus, the state of the art of LMD of GE4822 is extended by a modeling approach to predict the material's final characteristics depending on the initial process constraints regarding not only the microstructure but also the chemical composition and influence of subsequent heat treatments.

\section{EXPERIMENTAL WORK}

\section{A. Material}

The GE4822 (Ti-48Al-2Cr-2Nb at. pct) powder material used in this study is produced by TLS GmbH \& Co. $\mathrm{KG}$ via electrode induction melting gas atomization (EIGA). The inert gas used for atomization is argon. The processed powder fraction consists of particles sized 20 to $90 \mu \mathrm{m}$. The particle size distribution is characterized by: $\mathrm{D} 10=27 \mu \mathrm{m}, \mathrm{D} 50=56 \mu \mathrm{m}$ and $\mathrm{D} 90=75$ $\mu \mathrm{m}$. A similar $\mathrm{Ti}-48 \mathrm{Al}-2 \mathrm{Cr}-2 \mathrm{Nb}$ at. pet cast material, approximately $60 \mathrm{~mm}$ long, $30 \mathrm{~mm}$ high and $4 \mathrm{~mm}$ wide, is used as substrate material.

\section{B. LMD Setup and Processing}

LMD experiments are performed on a three-axis CNC gantry machine. The laser beam sources are a 3 $\mathrm{kW} \mathrm{Nd:YAG} \mathrm{fiber} \mathrm{laser} \mathrm{for} 2$ and $1 \mathrm{~mm}$ beam diameter and a $2 \mathrm{~kW}$ diode laser for $0.6 \mathrm{~mm}$ beam diameter $\left(d_{\mathrm{s}}\right)$. For preheating, an induction generator with $18 \mathrm{~kW}$ maximum power and a rectangular induction coil, which completely surrounds the substrate material, are used. The coil moves in build direction $z$ simultaneously with the machining head with increasing build height of the part. The power of the induction generator $P_{\mathrm{I}}$ is constant at the maximum adjustable value, which generates a temperature of approximately $900{ }^{\circ} \mathrm{C}$ at the measuring point and thus in the substrate. By moving the induction coil along the build direction during the process, the heat introduced into the material at the respective process level can be assumed to be constant. Schemes of the setup and scanning strategy are depicted in Figure 1.

Optical and mechanical components as well as the preheating system are set inside an airtight sealed chamber. This chamber is completely filled with argon $4.6(<100$ ppm O) during the LMD process. The oxygen content is maintained by an inline regulated gas purification. For local shielding, an additional argon gas flow of approximately $10 \mathrm{~L} / \mathrm{min}$ is applied. The process parameters used are listed in Table I, including beam diameter $\left(d_{\mathrm{s}}\right)$, feed rate $\left(v_{\mathrm{v}}\right)$, powder mass flow $\left(m_{\mathrm{g}}\right)$, horizontal track $\left(\Delta y_{\mathrm{s}}\right)$ and vertical layer $(\Delta z)$ offsets, laser power $\left(P_{\mathrm{L}}\right)$ and preheating temperature $\left(T_{\mathrm{V}}\right)$. The preheating temperature is constantly measured with a pyrometer. The power of the induction generator is automatically adjusted based on the measurement signals. LMD samples built are $10 \mathrm{~mm}$ in high, $4 \mathrm{~mm}$ wide and $60 \mathrm{~mm}$ long. The process duration is $55 \mathrm{~min}$ for $0.6 \mathrm{~mm}$ beam diameter, 17 minutes for $1 \mathrm{~mm}$ and 10 minutes for $2 \mathrm{~mm}$ beam diameter.

\section{Heat Treatment}

On selected samples, 4 hours of heat treatment at $1250{ }^{\circ} \mathrm{C}$, followed by cooling in air, is performed.

\section{Measurement and Analysis Methods}

With the measurement setup shown in Figure 1, the temperature of sample surfaces is measured thermographically during setup. To measure the temperature of the entire system in real time, a high-temperature infrared camera of the VarioTHERM ${ }^{\mathrm{TM}}$ head (InfraTec) type, which has been calibrated to the setup in advance by means of a ratio pyrometer, is used. The image

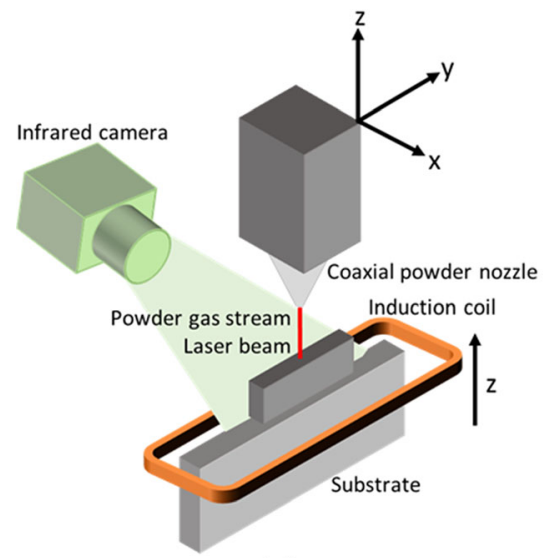

(a)

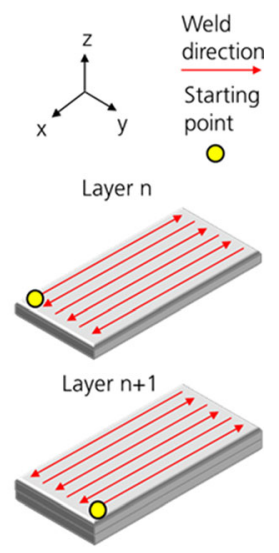

(b)
Fig. 1-Scheme of LMD setup (a) and strategy $(b)$. 
Table I. Overview of the Process Parameters Used to Build Up Samples with the Geometry of a Thin Wall $\left(n^{*} d_{\mathrm{s}} \times 10 \mathrm{~mm} \times\right.$ (10-60) $\mathrm{mm}$, with $\left.n * d_{\mathrm{s}} \leq 4 \mathrm{~mm}\right)$

\begin{tabular}{lccccccc}
\hline $\begin{array}{l}d_{\mathrm{s}} \\
{[\mathrm{mm}]}\end{array}$ & $\begin{array}{c}\text { Build Rate } \\
{\left[\mathrm{mm}^{3} / \mathrm{min}\right]}\end{array}$ & $\begin{array}{c}v_{\mathrm{v}} \\
{[\mathrm{mm} / \mathrm{min}]}\end{array}$ & $\begin{array}{c}m_{\mathrm{g}} \\
{[\mathrm{g} / \mathrm{min}]}\end{array}$ & $\begin{array}{c}\Delta y_{\mathrm{s}} \\
{[\mathrm{mm}]}\end{array}$ & $\begin{array}{c}\Delta z \\
{[\mathrm{~mm}]}\end{array}$ & $\begin{array}{c}P_{\mathrm{L}} \\
{[\mathrm{W}]}\end{array}$ & $\begin{array}{r}T_{\mathrm{V}} \\
{\left[{ }^{\circ} \mathrm{C}\right]}\end{array}$ \\
\hline 2 & 224 & 320 & 2.5 & 1 & 0.7 & 295 & 900 \\
1 & 75 & 500 & 2.0 & 0.5 & 0.3 & 200 & 900 \\
0.6 & 37.5 & 500 & 1.5 & 0.3 & 0.25 & 66 & 900 \\
\hline
\end{tabular}

repetition frequency is set to $50 \mathrm{~Hz}$. The measuring accuracy corresponds to $\pm 2{ }^{\circ} \mathrm{C}$ at $30^{\circ} \mathrm{C}$ according to the manufacturer of the device.

Samples for the microstructure investigation are cut parallel to the build direction $(z)$ and prepared with standard metallographic methods. Analyses of the microstructure are performed with a SEM Gemini 1550 (Zeiss). The SEM is operated in the back-scatter electron (BSE) mode to use the $Z$ contrast for image analysis.

The global oxygen and aluminum content of samples and of the powders is analyzed by hot gas extraction (oxygen) or ICP-OES (aluminum).

The Vickers hardness (HV0.3) is measured using a Qness Q30A + tester with a test load of $300 \mathrm{~g}$ and an indentation time of 15 seconds. The distance between the measuring points is $0.5 \mathrm{~mm}$ in each case. Hardness curves are determined in the middle of the specimen cross sections parallel to the build direction $(z)$ with a total of 60 indentations per condition.

\section{E. Simulation}

The LMD process is modeled by solving the heat conduction equation for singular melt tracks. The model resembles the work of Pirch et al. ${ }^{[20]}$ The preheating temperature is varied to correspond the experimentally measured temperatures for different build heights (see Figure 3). The process parameters used correspond to those in Table I. Figure 2 shows an etched cross section of a single track as an example. The areas of track width, track height and track depth are marked. Those measures are taken to verify the simulation results. The assumption is that the error of the track geometry (difference simulation to experimental results) is proportional to the error of the calculated solidification conditions.

In the model the temperature dependency of the material properties is considered. The material properties used for the model are provided by external partners and determined as confidential. The latent heat of fusion is implemented with the method of effective heat capacity. The particle temperature is assumed to be constant $T_{p}=1000^{\circ} \mathrm{C}$, because without the proper knowledge of the spatial particle distribution in the nozzle jet (particle trajectories) along the laser beam path a more accurate calculation is not possible. The particle temperature is calculated based on the material properties and laser radiation-particle interaction time and is verified by more sophisticated simulation results.

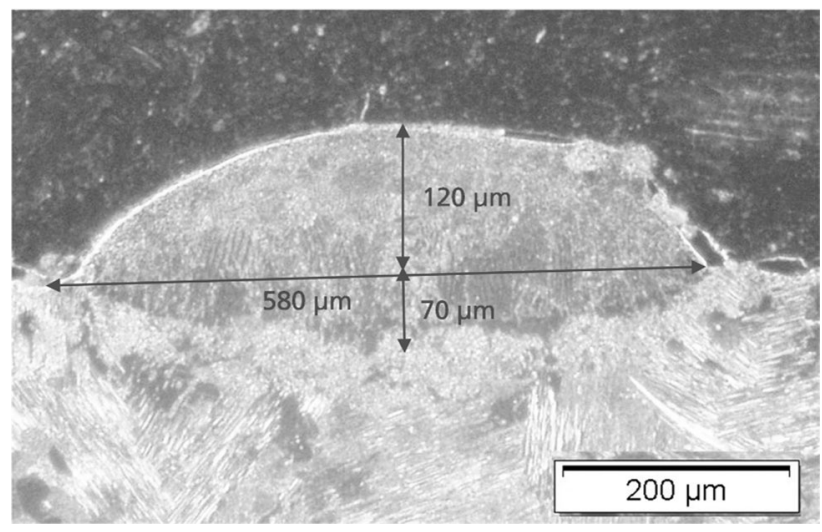

Fig. 2-Cross section of a single track (LMD) built with $d_{\mathrm{S}}=0.6 \mathrm{~mm}$.

The influence of the energy and mass of particles on the solution is only taken into account if a particle directly hits the melt pool surface. The melt pool currents and particle penetration depth are neglected. The shape of the melt track is calculated by solving the Young-Laplace equation for the mean surface curvature of the melt pool surface with the constraint of mass/volume conservation (with constant exterior pressure from the atmosphere). The laser radiation is implemented as a super Gaussian surface ( $n=2.5$ for "Gauss" and $n=12$ for "TopHat") source term, and the absorptivity of the material, solid as well as liquid, is assumed to be 0.4 . The visualization is done using the ParaView 5.4.0 program.

\section{RESULTS}

\section{A. Thermography}

\section{Cyclic re-heating}

Figure 3 shows the temperature curve of a fixed spatial point during the build-up of a layer for an explanatory construction height of $5 \mathrm{~mm}$.

The selected measurement point lies approximately 5 $\mathrm{mm}$ from the edge in the direction of application of the first of the 12 tracks that form a layer. The thermal influence of the adjacent tracks decreases with increasing distance from the measuring point (1st track). The applied material reaches temperatures of $>900{ }^{\circ} \mathrm{C}$ several times, which might significantly influence the microstructure formation in the solid phase, as can be seen from the CCT diagram for GE4822 elaborated in 


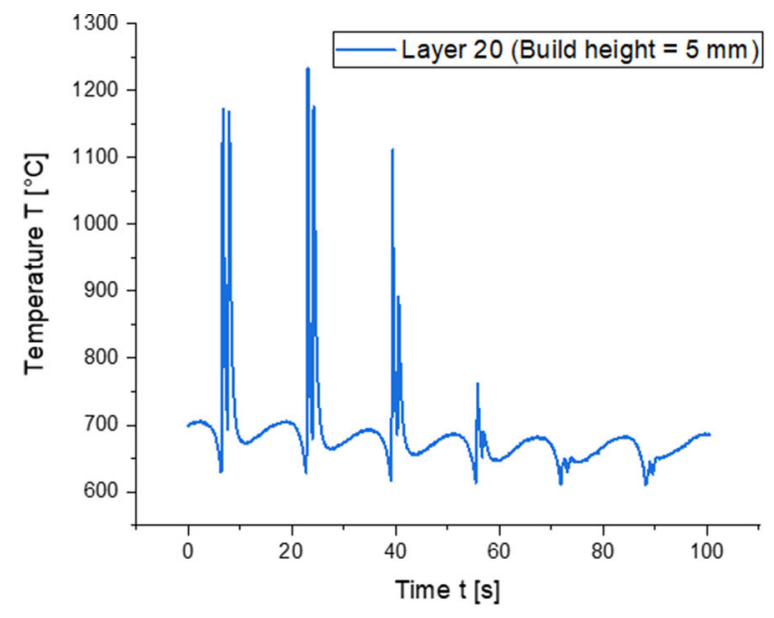

(a)

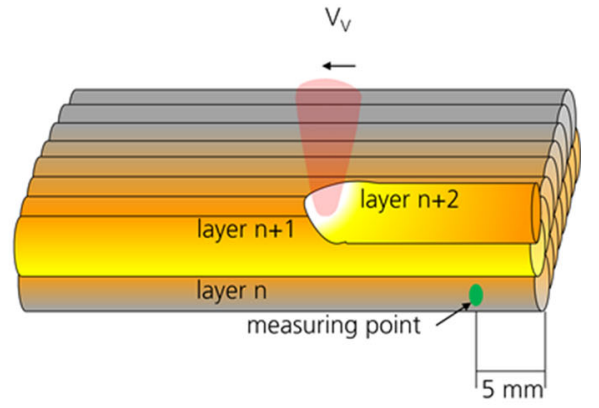

(b)

Fig. 3-Temperature decrease of a fixed point for successive exposure during $\mathrm{LMD}\left(\mathrm{GE} 4822, d_{\mathrm{S}}=0.6 \mathrm{~mm}, T_{\mathrm{V}}=900{ }^{\circ} \mathrm{C} ; a\right)$; schematic diagram of the measuring position $(b)$.

Reference 22. The authors found the amount of transformed $\alpha$-phase to be highly dependent on the cooling rates by which the transformation range can be extended to temperatures even well below $900{ }^{\circ} \mathrm{C}$ for cooling rates $>10^{\circ} \mathrm{C} / \mathrm{s}$, which applies to LMD. It is also noteworthy that the inert gas flow causes an additional cooling effect, which occasionally during the process cycle leads to temperatures below the preheating temperature.

\section{Influence of beam diameter on the actual pre-heating temperature}

Figure 4 shows the temperatures at the layer building start for various build heights for different beam diameters with a preheating temperature set to $900{ }^{\circ} \mathrm{C}$.

With a beam diameter of 1 and $2 \mathrm{~mm}$ at a build height of $5 \mathrm{~mm}$, maximum values of the measured starting temperatures are reached, and the temperatures drop when reaching $10 \mathrm{~mm}$ build height. With a beam diameter of $0.6 \mathrm{~mm}$, on the other hand, the starting temperature drops continuously. The temperature increase for 1 and $2 \mathrm{~mm}$ beam diameters is due to the greater amount of heat introduced by higher laser power compared to the parameter set with $0.6 \mathrm{~mm}$ beam diameter. Additionally, the total process time for the large beam diameters is reduced by a factor of about 3 $\left(d_{\mathrm{s}}=1 \mathrm{~mm}\right)$ respectively $5\left(d_{\mathrm{s}}=2 \mathrm{~mm}\right)$. Since the inert gas settings for all processes are the same, the inert gas cooling is more important for slower processes, thus decreasing the starting temperature for $d_{\mathrm{s}}=0.6 \mathrm{~mm}$. Due to the smaller number of tracks $\left(d_{s} \propto\right.$ track width $\rightarrow$ allowing increased heights), the integrated melt pool surface through which heat can be dissipated fast is also smaller. Compared to this, the cooling effects (surface, shielding gas flow) predominate over the heat input in a setup for a beam diameter of $0.6 \mathrm{~mm}$. This results in a decreasing preheating temperature with increasing build height.

The reduced preheating temperature in dependence on the build height is maximal at $10 \mathrm{~mm}$. A possible explanation is the overall larger sample volume and

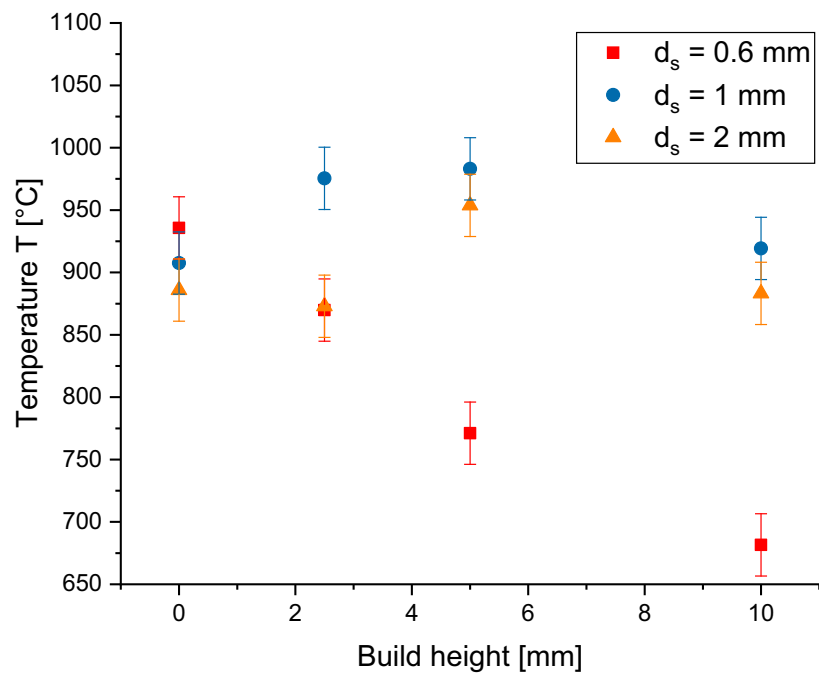

Fig. 4 - Layer start temperature as a function of build height during $\mathrm{LMD}, d_{\mathrm{S}}=0.6 ; 1 ; 2 \mathrm{~mm}$, set preheating $T_{\mathrm{V}}=900{ }^{\circ} \mathrm{C}$.

small thermal diffusivity of TiAl compared to other metals (approximately $8.5 \mathrm{~mm}^{2} / \mathrm{s}$ ). Additionally, temperature gradients perpendicular to the surface of the volume as well as between the surface and volume are likely to occur; in the context of induction, comparable effects are known as the sink effect. ${ }^{[23]}$ The measured values displayed would thus represent a spatially distorted image of the temperature distribution in the volume.

\section{B. Simulation}

1. Influence of beam diameter $@ T_{v}=900{ }^{\circ} \mathrm{C}$ on local solidification

In Figure 5, the temperature distributions from the FEM simulations for single melt tracks (virtually cut at symmetry) during LMD on similar preheated (to 


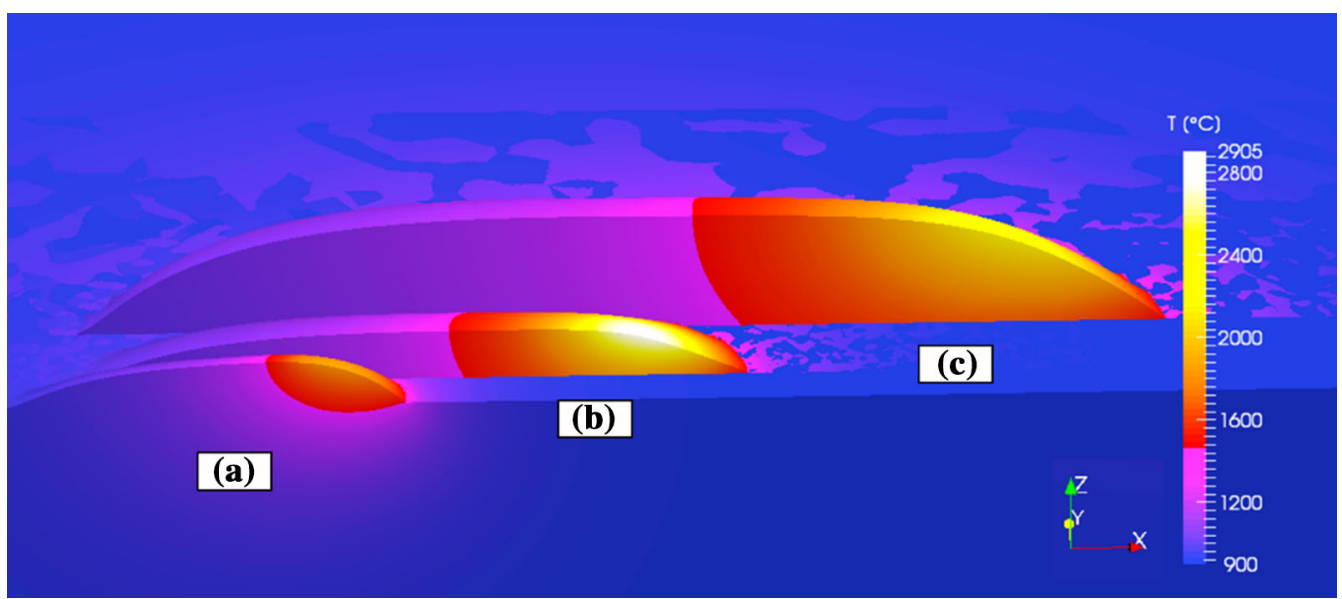

Fig. 5-Result of the melt pool simulation of single tracks (GE4822, LMD) for $d_{\mathrm{S}}=0.6 \mathrm{~mm}$ : (a) $1 \mathrm{~mm}(b) ; 2 \mathrm{~mm} ;(c)$ regarding temperature distribution.

$900{ }^{\circ} \mathrm{C}$ ) substrate material made of GE4822 are depicted.

Visible are solidified (blue-purple, $T \leq 1510{ }^{\circ} \mathrm{C}$ ) and molten areas of the traces (red-yellow-white, $T>1510$ ${ }^{\circ} \mathrm{C}$ ). Both the different melt pool dimensions and exceeding the aluminum boiling temperature of $2450{ }^{\circ} \mathrm{C}$ for 1 and $2 \mathrm{~mm}$ beam diameter can be recognized. According to the calculations, the maximum melt pool temperature of $2905{ }^{\circ} \mathrm{C}$ is reached at a beam diameter of $1 \mathrm{~mm}$. The reason for this is the intensity distribution, normalized to the maximum value shown in Figure 6. The average intensities are $I=93.9 \mathrm{~W} /$ $\mathrm{mm}^{2}\left(d_{\mathrm{S}}=2 \mathrm{~mm}\right) I=255 \mathrm{~W} / \mathrm{mm}^{2}\left(d_{\mathrm{S}}=1 \mathrm{~mm}\right)$ and $I=233 \mathrm{~W} / \mathrm{mm}^{2}\left(d_{\mathrm{S}}=0.6 \mathrm{~mm}\right)$. However, the graph (Figure 6) shows that the intensity in the center of the laser spot is much greater with a beam diameter of $1 \mathrm{~mm}$ than with diameters of 2 or $0.6 \mathrm{~mm}$. Therefore, the melt pool temperature in the center of the spot is also higher.

For comparison of the solidification conditions, the solidification rate, temperature change rate or cooling rate and local temperature gradients are important. The third can be calculated from any two of the values. Figure 7 shows the simulated cooling rates at the melt pool boundary as a function of the position on the solidification front.

Cooling rates $<0 \mathrm{~K} / \mathrm{s}$ depict heating of the material. The smaller the beam diameter, the higher the maximum cooling rate is. For a beam diameter of $0.6 \mathrm{~mm}$, the cooling rate is in the range of $10^{4} \mathrm{~K} / \mathrm{s}$, whereas with a beam diameter of $2 \mathrm{~mm}$, maximum cooling rates of the order of $10^{3} \mathrm{~K} / \mathrm{s}$ are achieved. The cooling rates determined by analysis of the thermographic data obtained in this study range from $10^{3}$ to $10^{2} \mathrm{~K} / \mathrm{s}$ on the surface of solidified tracks and thus are consistent with the model. In Reference 21 cooling rates for the LMD of single tracks made of GE4822 of about 5 to $1010^{4} \mathrm{~K} / \mathrm{s}$ for beam diameters of 0.5 to $2 \mathrm{~mm}$ are simulated. The process conditions used in the study for the modeling differ significantly in the preheating temperature, which is about $400{ }^{\circ} \mathrm{C}$, so that a reduction of cooling rates with increasing preheating temperature is to be expected.

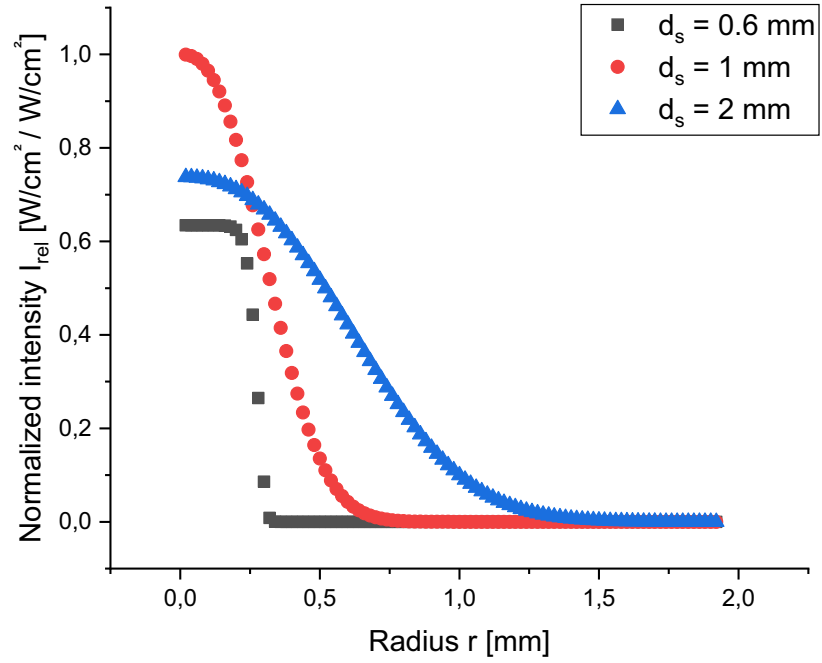

Fig. 6-Intensity (normalized) against beam radius for the laser beam diameter/laser power combinations used, measured with MicroSpotMonitor (Primes GmbH).

Figure 8 shows the solidification rates in scanning direction at the melt pool boundary for the different processing parameters.

Solidification rates $<0 \mathrm{~K} / \mathrm{s}$ indicate melting of the material. In comparison, solidification is faster for smaller beam diameters because of the fast scanning velocity used. Thus, a clear expression of dendritic microstructure morphology is expected in samples built with small beam diameters $(0.6$ and $1 \mathrm{~mm})$. At the same time, the cooling rate for calculations with $d_{\mathrm{S}}=0.6 \mathrm{~mm}$ is considerably higher than with 1 or $2 \mathrm{~mm}$ beam diameters, so that a comparatively finer microstructure is expected.

The respective maximum melt pool temperatures, maximum temperature gradients to the solid phase and maximum cooling rates are listed in Table II to allow quantitative comparison. 


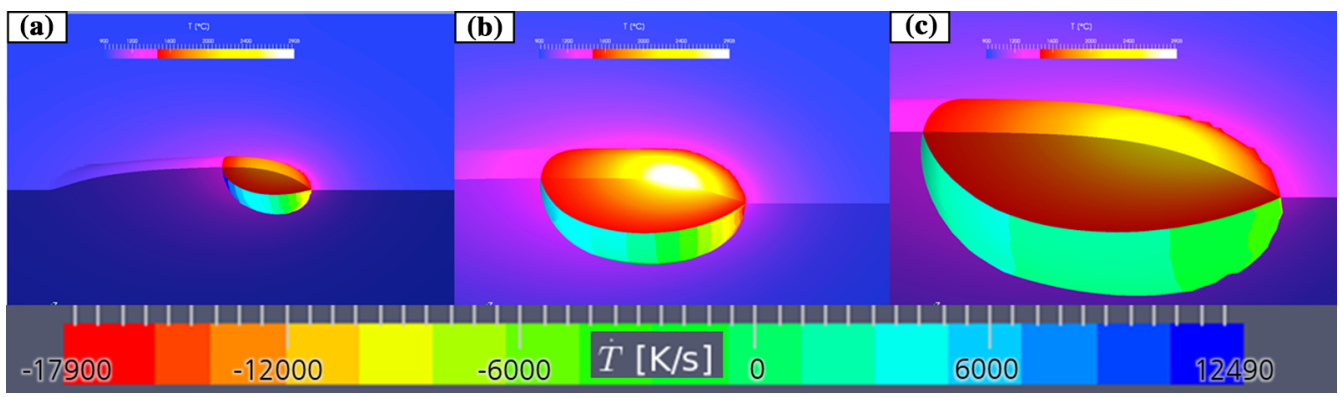

Fig. 7-Result of the melt pool simulation of single tracks (GE4822, LMD) for $d_{\mathrm{S}}=0.6(a) 1$ and (b) 2 mm (c) regarding the cooling rate.

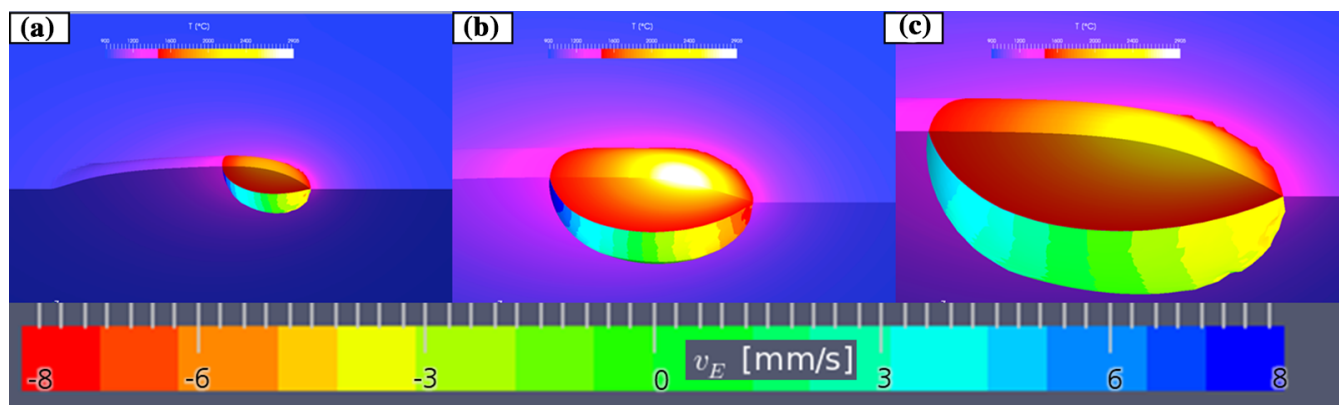

Fig. 8-Result of the melt pool simulation of single tracks (GE4822, LMD) for $d_{\mathrm{S}}=0.6(a) 1$ and $(b) 2$ mm $(c)$ regarding the solidification rate.

\section{Influence of preheating temperature on local solidification}

The results of the melt pool simulation using the measured preheating temperatures (see Figure 4), which depend on the build height, are shown in Figure 9. It is evident that there is no significant dependence of the cooling rate on the build height for $d_{\mathrm{s}}=1$ and $d_{\mathrm{s}}=2 \mathrm{~mm}$. This fits reasonably well with the small differences in the preheating temperatures. Therefore, a correspondingly homogeneous microstructure can be expected. The cooling rates when using a smaller beam diameter vary according to the local preheating temperatures over the build height, but are all in the range of $10^{3} \mathrm{~K} / \mathrm{s}$.

The influence of the process parameters used on the microstructure is expected to be visible. For the sample built with $d_{\mathrm{s}}=0.6 \mathrm{~mm}$, the microstructure is considered separately as a function of the build height because of the significant differences expected.

\section{Microstructure Analysis}

1. Homogeneity over build height $\left(=T_{V}\right)$ for $d_{S}=0.6 \mathrm{~mm}$

The macroscopic homogeneity of the samples can be examined exemplarily in Figure 10. Identical high individual layers are visible over the vertical structure with differences between the track and track edge areas that can be recognized by the constantly alternating shading.

In addition, Figure 10 also shows constant differences between the sample edges (left and right) and the middle of the sample. When looking at individual sections in detail, the process-related track and layer structure can be seen (Figure 11). Slight differences in microstructure fineness and morphology are visible depending on whether track edge or middle areas are considered. Beyond these regularly alternating areas, no differences in the microstructure are visible depending on the height of the structure.

After heat treatment, individual traces and layers are no longer visible, and the microstructure is homogenized (Figure 12).

Hardness measurements taken vertically in the middle of the as-built sample (Figure 13) show no significant, but nevertheless recognizable tendencies of hardness, being dependent on the build height. It was assumed that especially the fineness and thus the hardness of the microstructure could depend on the height of the structure because of the differences in preheating and reheating during the process. This assumption is confirmed by neither SEM images nor this measurement's results.

The increased reheating due to the build-up of superimposed layers in the lower sample areas and the overall higher temperature nevertheless might result in differences in the local phase distribution and thus in lower hardness of the material reheated in this way over a longer time period. Additionally, a harder top zone due to a higher oxygen content through surface oxidation of the edge area is assumed to be the cause for the notable increased hardness values on the upper edge of the sample, even after heat treatment. While the samples slowly cool down after the process, the additional shielding gas flow is off, which allows for additional oxidation and oxygen diffusion in all near-surface regions. This is not essentially relevant for application, as surface regions will regularly be removed in subsequent finishing steps. 
2. Influence of beam diameter for $T_{V}=900{ }^{\circ} \mathrm{C}$ on chemical composition and microstructure

In Table III, the measured oxygen and aluminum contents of the examined samples are listed.

Table II. Summary of Representative Results from the Melt Pool Simulation for $T_{\mathrm{V}}=900^{\circ} \mathrm{C}(\mathrm{GE4822}, \mathrm{LMD})$

\begin{tabular}{lcll}
\hline Laser Beam Diameter $d_{\mathrm{S}}[\mathrm{mm}]$ & 0.6 & 1 & \multicolumn{1}{c}{2} \\
\hline Maximum Melt Pool Temperature $\left[{ }^{\circ} \mathrm{C}\right]$ & 1962 & 2905 & 2458 \\
Maximum Temperature Gradient to & 1499 & 651 & 346 \\
$\quad$ Solid Phase $[\mathrm{K} / \mathrm{mm}]$ & & & \\
Maximum Cooling Rate at Solidification & 12.5 & 5.4 & 1.8 \\
$\quad$ Front $\left[10^{3} \cdot \mathrm{K} / \mathrm{s}\right]$ & & & \\
\hline
\end{tabular}

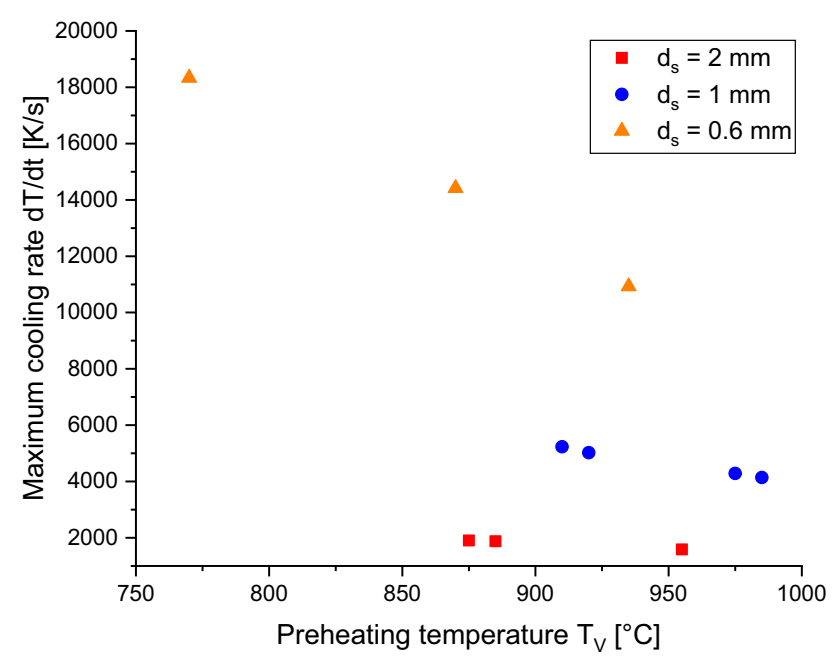

Fig. 9-Maximum cooling rates from the melt pool simulation of single tracks (GE4822, LMD).
The oxygen content increases significantly as the beam diameter is reduced, although the material and process conditions are identical. The only other source of oxygen besides the powder material is the residual oxygen content of the inert gas atmosphere, which is $<50 \mathrm{ppm} \mathrm{O}$ during the process. All of the process parameter-dependent influences during the process are complex, such as the cooling effect of inert gas flows, shading effects caused by powder particles and surface effects. However, the correlation between laser beam diameter or build-up rate and oxygen content is obvious. The reason for this is due to the smaller melt pool surface area, integrated over the process time, exposed to the residual oxygen-containing process atmosphere when using a larger laser beam diameter. The integrated melt pool surface $A_{S}$ of a sample is the result of the calculation based on melt pool width $b_{\mathrm{S}}$, track distance $\Delta y_{\mathrm{s}}$, layer thickness $\Delta z$ and sample height $H$, width $B$ and length $L$

$$
A_{S}=b_{S} \cdot\left(\frac{B}{\Delta y_{s}}-1\right) \cdot\left(\frac{H}{\Delta z}\right) \cdot L
$$

without consideration of edge effects and surface curvature. Values for the process parameters used, in each case normalized by division by the sample volume, are listed in Table IV.

The cooling rate of the melt is regarded as a further critical variable. This determines the dwell time in the molten state during which oxygen absorption primarily takes place. At $d_{\mathrm{S}}=2 \mathrm{~mm}$, the cooling rate of the melt is about half as great as when using a laser beam diameter of $0.6 \mathrm{~mm}$. Nevertheless, the total surface per time exposed to the environment in the molten state is still much smaller when using the larger beam diameter.

The global aluminum evaporation for all investigated samples is coherent with the literature references. This amounts to $<1 \mathrm{wt}$ pct evaporation for LMD and LPBF
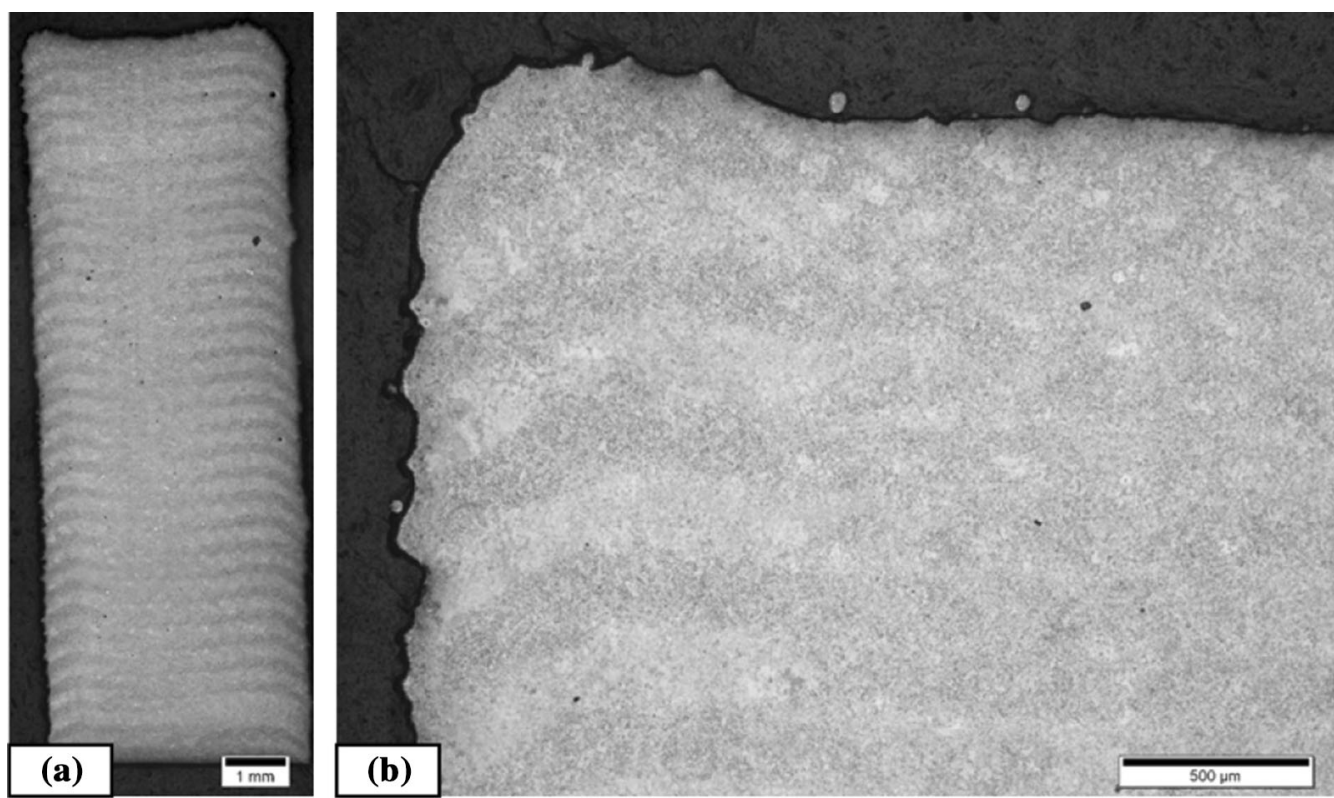

Fig. 10-Light microscope overview (a) and detail (b) of a TiAl sample (LMD), $d_{\mathrm{S}}=0.6 \mathrm{~mm}$, as-built. 


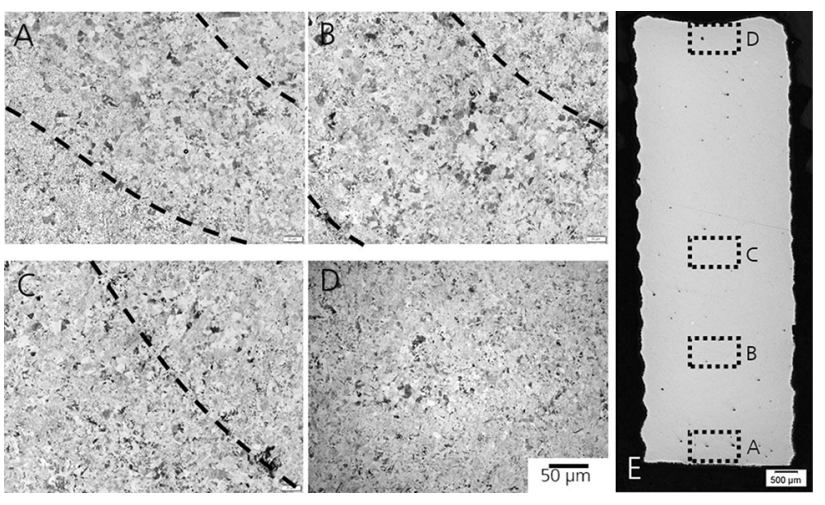

Fig. 11-Light microscope overview (e) of a TiAl sample (LMD), $d_{\mathrm{S}}$ $=0.6 \mathrm{~mm}, D=4 \mathrm{~mm}$, as-built, and details: bottom ( $a$ to $b$ ), middle (c) and top region $(d)$.
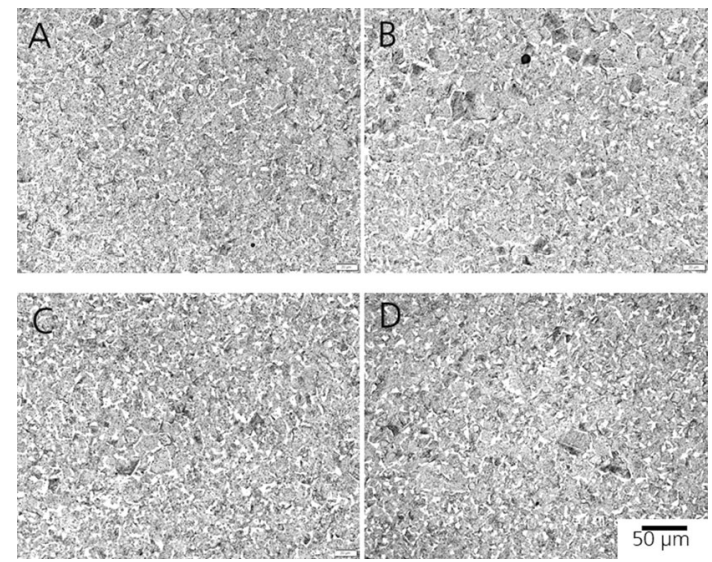

Fig. 12-Details from the light microscope overview of a TiAl sample (LMD), $d_{\mathrm{S}}=0.6 \mathrm{~mm}, D=4 \mathrm{~mm}$, in heat-treated condition: bottom ( $a$ to $b)$, middle $(c)$ and top region $(d)$.

Table III. Chemical Composition Regarding Oxygen and Aluminum Content (GE4822, LMD)

\begin{tabular}{lcccc}
\hline Laser Beam Diameter $d_{\mathrm{S}}[\mathrm{mm}]$ & Powder & 0.6 & 1 & 2 \\
\hline Oxygen Content [ppm] & 720 & 1700 & 1500 & 1100 \\
Aluminum Content [wt pct] & 33.15 & 32.7 & 33.05 & 33.05 \\
\hline
\end{tabular}

and approximately $1 \mathrm{wt}$ pct or higher evaporation in EBM. ${ }^{[8,12,24]}$ The evaporation is highest when using a beam diameter of $0.6 \mathrm{~mm}$. According to Reference 24 evaporation is primarily proportional to the line energy $E_{\mathrm{S}}$. Since evaporation is a surface effect, the beam diameter $d_{\mathrm{S}}$ is also relevant. Thus, the surface energy $E_{\mathrm{A}}$ can be formulated as

$$
E_{A}\left[\frac{J}{m m^{2}}\right]=\frac{E_{S}}{d_{S}}=\frac{P_{L}}{v \cdot d_{S}}
$$

with laser power $P_{\mathrm{L}}$ and scan speed $v$ in $\mathrm{mm} / \mathrm{s}$. This results in the values listed in Table $\mathrm{V}$ for the area energy of the parameter sets used.
It is assumed that during the process the aluminum evaporation temperature $\left(2450{ }^{\circ} \mathrm{C}\right)$ is reached and, with greater surface energy, also higher temperatures at the surface of the melt pool. The use of the surface energy as the sole criterion is therefore not consistent with the measurement results, as this would imply the aluminum evaporation is highest when using a beam diameter of 2 $\mathrm{mm}$. If the melt pool temperatures (Table II) are taken into account, a maximum aluminum evaporation would have to be assumed when using a beam diameter of 1 $\mathrm{mm}$. Thus, the measurement results can be mainly justified by the larger melt pool surface that adds up over the total time of the build-up when using a beam diameter of $0.6 \mathrm{~mm}$. In total, no definite statement can be made because of both the small deviations of the measured values from one another and the standard error for chemical analysis being expected to be in the range of at least 0.1 pct.

Figure 14 compares LMD microstructures of GE4822 observed using SEM-BSE with different beam diameters. The grain size increases visibly using a larger beam diameter (Figures 14(b) through (d)). Uniformly visible is the heterogeneous microstructure with very fine lamellar, non-measurable amounts of $\alpha_{2}+\gamma$ as well as structureless $\gamma$ matrix with blocky single $\alpha_{2}$ phase.

The LMD process itself provides high cooling rates and numerous cycles of reheating at elevated temperatures by which the resulting share of lamellar $\alpha_{2}+\gamma$ is supposed to be influenced. According to Reference 23 high cooling rates support the $\alpha \rightarrow \alpha_{2}+\gamma$ transformation by extending the transformation range even resulting in feathery or Widmanstaetten features. This leads to the assumption that with higher cooling rates - in the study represented by using a beam diameter of 0.6 $\mathrm{mm}$ - the share of lamellar phase is higher compared to when using a larger beam diameter and thus provides lower cooling rates, respectively. However, the amount of $\gamma$ seems to be especially high for the smallest beam diameter. For samples made of GE4822 produced by EBM, Reference 25 discusses to what extent the $\alpha$ phase is the result of incomplete massive $\gamma$ transformation or nucleation from massive $\gamma$ phase at high process temperatures. The literature indicates that cooling rates of several $100 \mathrm{~K} / \mathrm{s}^{[26]}$ are sufficient to trigger the massive $\gamma$ transformation. In the AM process, the conditions for the formation of massive $\gamma$ are then given. Reference 27 for example, shows how $\alpha_{2}$ plates are formed within $\gamma_{\mathrm{m}}$ grains of a Ti-46Al-9Nb alloy by 1-hours heat treatment at $1200{ }^{\circ} \mathrm{C}$. The process behind this is a transformation of $\gamma_{\mathrm{m}}$ into a $\alpha_{2}+\gamma$ duplex structure. Regarding the $\alpha_{2}$ phase visible in Figure 14(a), an interpretation of this is at least locally obvious, as can be seen from the "nested" $\alpha_{2}$ within $\gamma$. In Reference 28 investigations on Ti-48Al-2Nb-2Cr (GE4822) show that a heat treatment at $900{ }^{\circ} \mathrm{C}$ to $1000{ }^{\circ} \mathrm{C}$, held for 30 seconds, could be sufficient for the transformation of the $\alpha_{2}$ plates. Due to this and the knowledge from Figure 3 that these temperature ranges are reached and passed through several times by already welded solid state material, the variant of $\alpha_{2}$ nucleation from a massive $\gamma$ phase discussed in Reference 25 seems probable. No indications of massive $\gamma$ formation are visible in the 

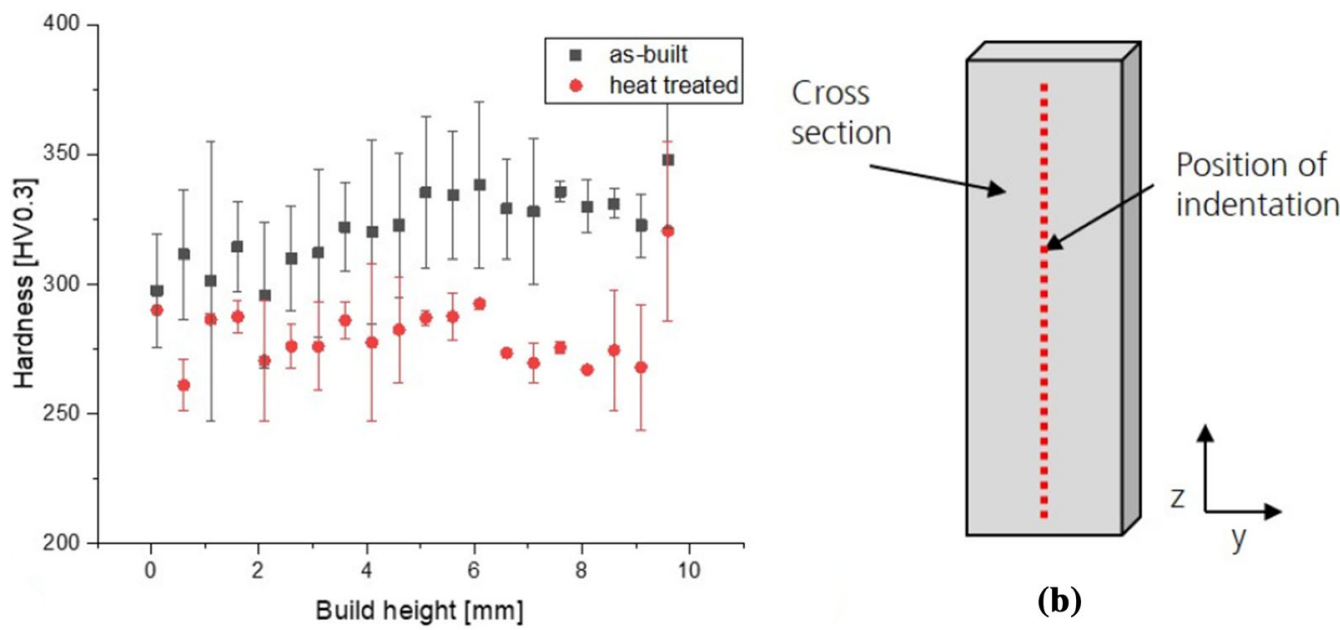

(a)

Fig. 13-Hardness over build height using the example of LMD walls (GE4822), $d_{\mathrm{S}}=0.6 \mathrm{~mm}$, as-built (a), schematic diagram of the measurement position $(b)$.

Table IV. Integrated Melt Pool Surface Dependent on the Beam Diameter

\begin{tabular}{llrl}
\hline Laser Beam Diameter $d_{\mathrm{S}}[\mathrm{mm}]$ & 0.6 & 1 & 2 \\
\hline Normalized Integrated Melt Pool Surface $a_{S}\left[\mathrm{~mm}^{2}\right.$ pro $\left.\mathrm{mm}^{3}\right]$ & 7.2 & 5.8 & 2.1 \\
\hline
\end{tabular}

Table V. Surface Energy Depending on the Parameter Set

\begin{tabular}{lccc}
\hline Laser Beam Diameter $d_{\mathrm{S}}[\mathrm{mm}]$ & 0.6 & 1 & 2 \\
\hline Surface Energy $E_{\mathrm{A}}\left[\mathrm{J}\right.$ per $\left.\mathrm{mm}^{2}\right]$ & 13.2 & 24 & 27.7 \\
\hline
\end{tabular}

microstructures of samples built up with $d_{\mathrm{S}}=1$ and 2 $\mathrm{mm}$. This observation is consistent with the description documented in Reference 29 that larger proportions of massive $\gamma$ phase are formed with higher cooling rates.

Figure 15 shows the microstructures of GE4822 material laser clad with different parameter sets after 4 hour of heat treatment at $1250{ }^{\circ} \mathrm{C}$ followed by cooling in air.

After the heat treatment, a microstructure consisting of $\alpha_{2}-\mathrm{Ti}_{3} \mathrm{Al}$ and $\gamma$-TiAl is present in all samples. In cross sections of the heat-treated samples built with 1 and 2 $\mathrm{mm}$ beam diameter, in contrast to the one built with 0.6 $\mathrm{mm} d_{\mathrm{s}}$, larger portions of lamellar $\gamma+\alpha_{2}$ grains are visible. According to this, the phase transformation during cooling takes place via the $\gamma+\alpha_{2}$ phase region. The $\alpha_{2}$ phase fraction is visually smaller in all samples than before the heat treatment.

From the hardness test (Figure 16), despite the visibly coarser grains in samples built up with $d_{\mathrm{S}}=1$ and $2 \mathrm{~mm}$, no significant difference is apparent. However, the visual impression that in the as-built state the proportion of softer $y$-phase (compared to the $\alpha_{2}$ or lamellar phase) is higher in samples produced with $d_{\mathrm{s}}=0.6 \mathrm{~mm}$ is coherent with the results. The lamellar distances are also an influencing factor to be considered.

With heat treatment, existing differences in the microstructure within the respective samples are almost completely compensated (Figure 12). The microhardness is reduced throughout, mainly by grain coarsening and the decrease of $\alpha_{2}$ phase fraction. Within the scope of the measurement deviations, no significant differences were found even after heat treatment.

\section{CONCLUSION}

In the present study, the solidification conditions and their influence on chemical composition and microstructure during laser cladding of the TiAl alloy GE4822 are investigated by both experimental measurements and simulation.

(i) The local cooling conditions, primarily evaluated based on the cooling rate of the molten pool, are largely homogeneous within manufactured specimens when viewed over the structural height and are of the same order of magnitude.

(ii) The local cooling conditions are significantly influenced by the choice of process parameters. The cooling rate when using a small beam diameter $\left(d_{\mathrm{s}}=0.6 \mathrm{~mm}\right)$ and thus small melt pools is greater by a factor of 10 than when using larger beam diameters $\left(d_{\mathrm{s}}=1\right.$ or $\left.2 \mathrm{~mm}\right)$. These differences are reflected in the 

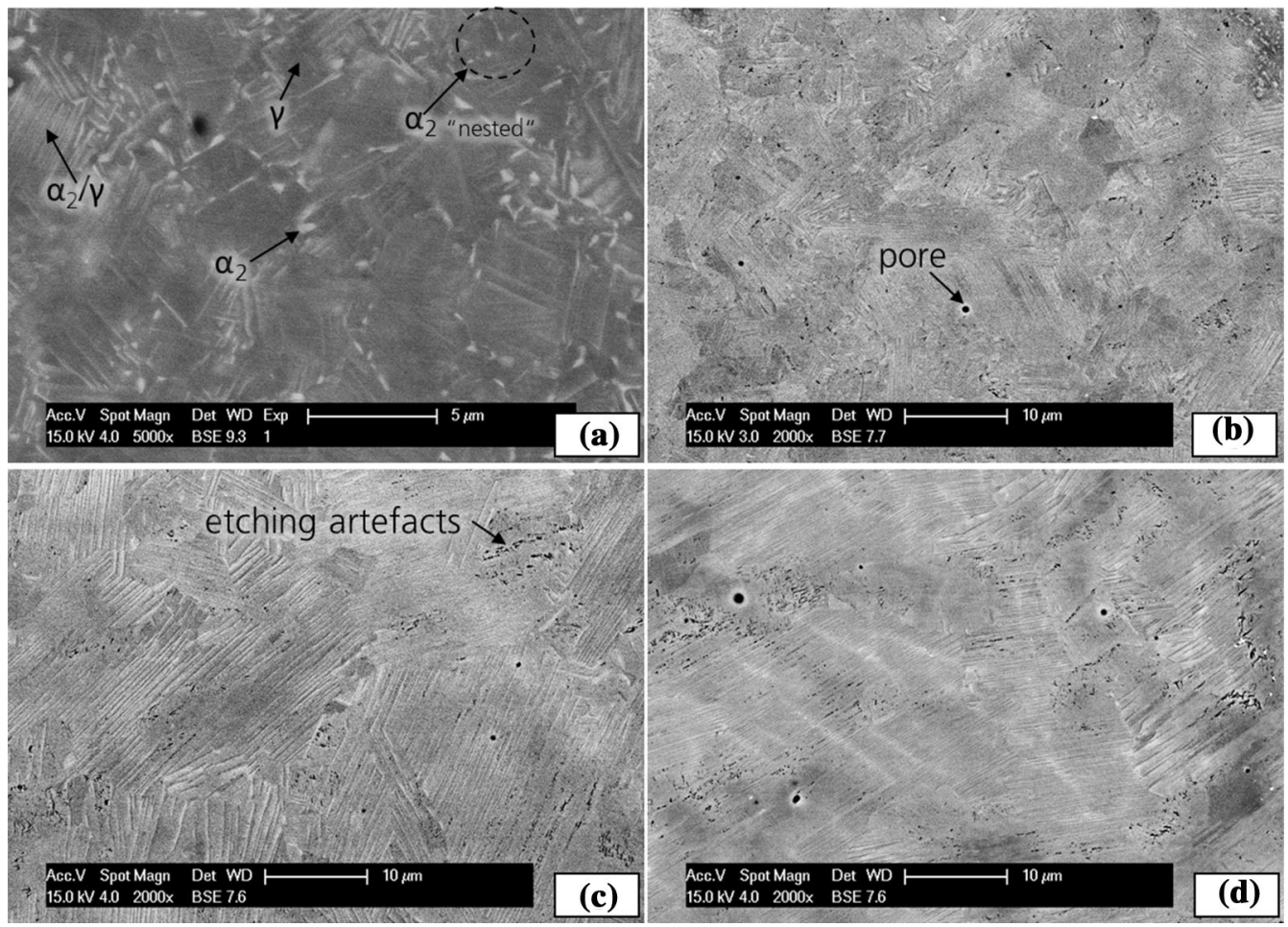

Fig. 14 SEM-BSE images of LMD material (GE4822), built with $d_{\mathrm{S}}=(a, b) 0.6 \mathrm{~mm},(c) 1 \mathrm{~mm}$ and (d) $2 \mathrm{~mm}$, cross sections, as-built, (b), (c) and (d) in etched condition.
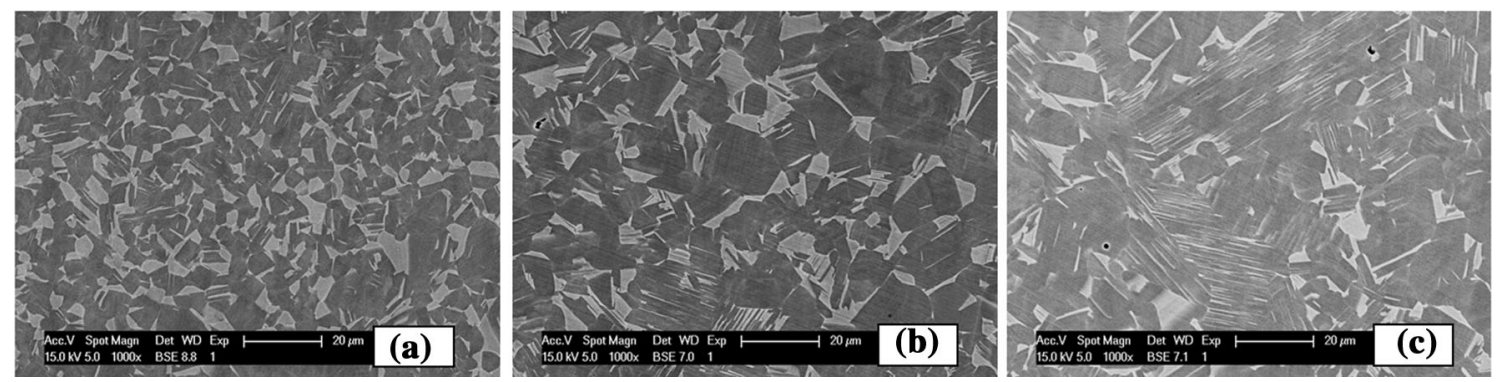

Fig. 15-SEM-BSE images of LMD material (GE4822), built with $d_{\mathrm{S}}=(a) 0.6 \mathrm{~mm},(b) 1 \mathrm{~mm},(c) 2 \mathrm{~mm}$, cross sections, in heat-treated condition $\left(1250^{\circ} \mathrm{C}, 4 \mathrm{~h}, \mathrm{ac}\right)$.

microstructure of the produced samples, visible by the resulting grain sizes and phases.

(iii) The choice of process parameters also influences the chemical composition, in particular the oxygen uptake. This increases with smaller beam diameter. The larger integrated melt pool surface over the total sample volume is assumed to be a significant effect.

(iv) Heat treatment visibly homogenizes the structure and diminishes visible differences. However, the grain sizes of specimens produced with different process parameters are not completely adjusted to each other.

(v) Regardless of the observed influences and the heat treatment, no influence of the process parameter selection on the microhardness is reported.
It was shown that the modeling approach used can obtain consistent results with experimental investigations and how solidification conditions for LMD of TiAl can also be specifically modified by process management. If the model is extended to the temperature field of the entire component, it is possible to extrapolate microstructural and thus in the next step mechanical properties. In addition, process parameters could be adapted locally so that constant solidification conditions can be produced within the component. Current research aspects include the detailed investigation of microstructural differences and the possible influence on application-relevant mechanical properties such as strength and creep resistance, which will be published separately. 


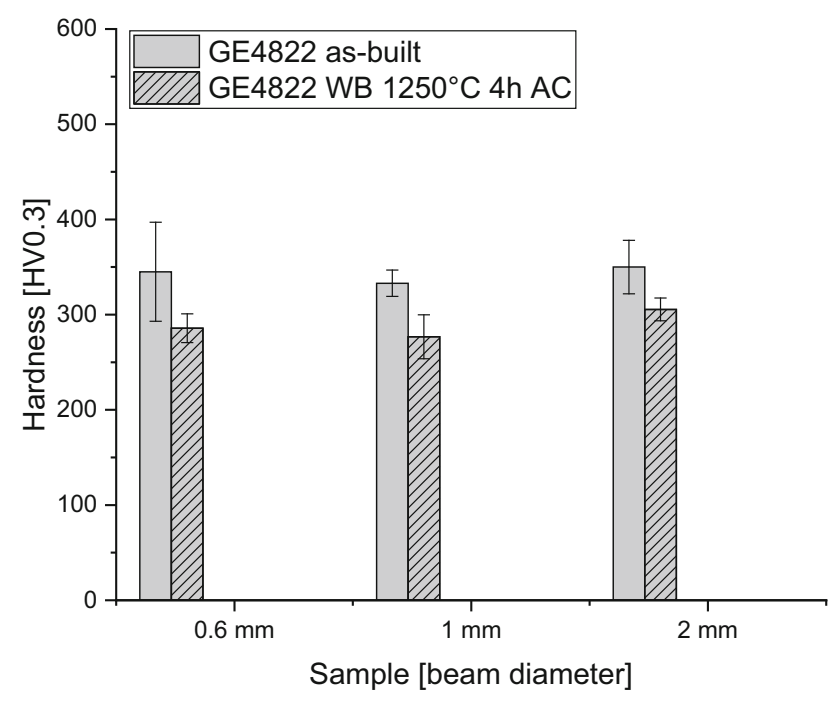

Fig. 16-Hardness against beam diameter, before and after heat treatment (GE4822, LMD).

\section{ACKNOWLEDGMENTS}

This work was partly supported by the German Federal Ministry for Economic Affairs and Energy BMWi (Grant Number 20T1311). The presented investigations were partly conducted in the context of the Collaborative Research Centre SFB1120 "Precision Melt Engineering" at RWTH Aachen University and funded by the German Research Foundation (DFG). For the sponsorship and support we wish to express our sincere gratitude.

\section{FUNDING}

Open Access funding enabled and organized by Projekt DEAL.

\section{OPEN ACCESS}

This article is licensed under a Creative Commons Attribution 4.0 International License, which permits use, sharing, adaptation, distribution and reproduction in any medium or format, as long as you give appropriate credit to the original author(s) and the source, provide a link to the Creative Commons licence, and indicate if changes were made. The images or other third party material in this article are included in the article's Creative Commons licence, unless indicated otherwise in a credit line to the material. If material is not included in the article's Creative Commons licence and your intended use is not permitted by statutory regulation or exceeds the permitted use, you will need to obtain permission directly from the copyright holder. To view a copy of this licence, visit http://creat ivecommons.org/licenses/by/4.0/.

\section{REFERENCES}

1. S. F. Clark, 787 Propulsion System. (Boeing Aero, 2012), https:// www.boeing.com/commercial/aeromagazine/articles/2012_q3/2/. Accessed 26 Aug 2019

2. Motor Presse Stuttgart GmbH \& Co. KG, MTU entwickelt neuen Werkstoff für Turbinenschaufeln (2015), https://www.flugrevue. de/flugzeugbau/titanaluminid-mtu-entwickelt-neuen-werkstoff-fue r-turbinenschaufeln/. Accessed 26 August 2019.

3. GfE Metalle und Materialien GmbH, TiAl48-2-2 (2017), https:// www.gfe.com/produktbereiche/titanaluminide/produktuebersicht/ . Accessed 10 Dec 2020.

4. Y. Du, J. Shen, Y. Xiong, Z. Shang, and H. Fu: Intermetallics, 2015, vol. 61, pp. 80-84.

5. V. Tebaldo and M.G. Faga: J. Mater. Process. Technol., 2017, vol. 244, pp. 289-303.

6. A. Penna: PhD thesis, Politecnico di Torino, Torino, 2013.

7. G. Baudana, S. Biamino, D. Ugues, M. Lombardi, P. Fino, M. Pavese, and C. Badini: Metal Powder Rep., 2016, vol. 3, pp. 193-99.

8. S. Biamino, A. Penna, U. Ackelid, S. Sabbadini, O. Tassa, P. Fino, M. Pavese, P. Gennarao, and C. Badini: Intermetallics, 2011, vol. 6, pp. 776-81.

9. H.P. Tang, G.Y. Yang, W.P. Jia, W.W. He, S.L. Lu, and M. Qian: Mater. Sci. Eng. A, 2015, vol. 636, pp. 103-107.

10. S. Biamino, B. Klöden, T. Weißgärber, B. Kieback, and U. Ackelid: World PM, 2014, vol. 03, pp. 96-103.

11. General Electric Company, Additive at Scale: Avio Aero Flies into the Future (2018), https://www.ge.com/additive/stories/additive-a t-scale-avio-aero. Accessed Nov 162020.

12. M.S. Dahar, S.M. Seifi, B.P. Bewlay, and J.J. Lewandowski: Intermetallics, 2015, vol. 57, pp. 73-82.

13. W. Ge, C. Guo, and F. Lin: Procedia Eng., 2014, vol. 81, pp. $1192-97$.

14. J. Gussone, Y.-C. Hagedorn, H. Gherekhloo, G. Kasperovich, T. Merzouk, and J. Hausmann: Intermetallics, 2015, vol. 66, pp. $133-40$.

15. L. Löber, F.P. Schimansky, U. Kühn, F. Pyczak, and J. Eckert: $J$. Mater. Process. Technol., 2014, vol. 9, pp. 1852-60.

16. A. Vogelpoth, J.H. Schleifenbaum, and S.-K. Rittinghaus: Proc. ASME Turbo Expo 2019: Turbomachinery, 2019, vol. 6, p. 11.

17. M. Thomas, T. Malot, and P. Aubry: Metall. Trans. A, 2017, vol. 193A, pp. 519-37.

18. S.-K. Rittinghaus, U. Hecht, V. Werner, and A. Weisheit: Intermetallics, 2018, vol. 95, pp. 94-101.

19. T. Vilaro, V. Kottman-Rexerodt, M. Thomas, C. Colin, P. Bertrand, L. Thivillon, S. Abed, V. Ji, P. Aubry, P. Peyre, and T. Malot: $A M R, 2010$, vols. 89-91, pp. 586-91.

20. C. Zhong, P. Pirch, A. Gasser, R. Poprawe, and J. Schleifenbaum: Metals, 2017, vol. 10, pp. 156-43.

21. J. Wilden, H. Frank, C. Theiler, T. Seefeld, G. Sepold: 47. Int. Wiss. Kolloquium, TU Ilmenau, Ilmenau, 2002, pp. 445-47.

22. M. Charpentier, A. Hazotte, and D. Daloz: Mater. Sci. Eng. A, 2008, vols. 1-2, pp. 321-30.

23. V.I. Rudnev and D. Loveless: Compr. Mater. Proc., 2014, vol. 12, pp. 489-80.

24. A. Klassen, V.E. Forster, V. Juechter, and C. Körner: J. Mater. Process. Technol., 2017, vol. 247, pp. 280-88.

25. J. Schwerdtfeger and C. Körner: Intermetallics, 2014, vol. 49, pp. 29-35.

26. D. Hu, A.J. Huang, and X. Wu: Intermetallics, 2007, vol. 3, pp. 327-32.

27. A. Bartels, S. Bystrzanowski, H. Chladil, H. Leitner, H. Clemens, R. Gerling, and F.-P. Schimansky: MRS Proc., 2004, vol. 842, p. 2369.

28. U. Prasad and M.C. Chaturvedi: Metall. Trans. A, 2003, vol. 10A, pp. 2053-66.

29. Q. Xia, J.N. Wang, J. Yang, and Y. Wang: Intermetallics, 2001, vol. 5, pp. 361-67.

Publisher's Note Springer Nature remains neutral with regard to jurisdictional claims in published maps and institutional affiliations. 